\title{
Inflammatory Effects of Phthalates in Neonatal Neutrophils
}

\author{
ANNA M. VETRANO, DEBRA L. LASKIN, FAITH ARCHER, KIRIN SYED, JOSHUA P. GRAY, JEFFREY D. LASKIN, \\ NKIRU NWEBUBE, AND BARRY WEINBERGER
}

\begin{abstract}
Departments of Pediatrics [A.M.V., F.A., K.S., N.N., B.W.] and Environmental and Occupational Medicine [J.D.L.], University of Medicine and Dentistry of New Jersey-Robert Wood Johnson Medical School, New Brunswick, New Jersey 08901; Department of Pharmacology and Toxicology [D.L.L.], Rutgers University, Piscataway, New Jersey 08854; US Coast Guard Academy [J.P.G.], New
\end{abstract} London, Connecticut 06320

\begin{abstract}
Hospitalized infants are exposed to numerous devices containing the plasticizer di-(2-ethylhexyl) phthalate. Urinary levels of the phthalate metabolite, mono-(2-ethylhexyl) phthalate (MEHP), are markedly elevated in premature infants. Phthalates inactivate peroxisome proliferator-activated receptor- $\gamma$ (PPAR- $\gamma$ ), a nuclear transcription factor that mediates the resolution of inflammation, a process impaired in neonates. We speculate that this increases their susceptibility to MEHP, and this was analyzed. MEHP inhibited neutrophil apoptosis; neonatal cells were more sensitive than adult cells. In neonatal, but not in adult neutrophils, MEHP also inhibited chemotaxis, stimulated oxidative metabolism, and up-regulated expression of NADPH oxidase-1. In both adult and neonatal neutrophils, MEHP stimulated IL-1 $\beta$ and VEGF production, whereas IL-8 production was stimulated only in adult cells. In contrast, MEHPinhibited production of MIP- $1 \beta$ by adult cells, and Regulated on Activation Normal T Cell Expressed and Secreted (RANTES) by neonatal neutrophils. The effects of MEHP on apoptosis and oxidative metabolism in neonatal cells were reversed by the PPAR- $\gamma$ agonist, troglitazone. Whereas troglitazone had no effect on MEHPinduced alterations in inflammatory protein or chemokine production, constitutive IL- 8 and MIP- $1 \beta$ production was reduced in adult neutrophils, and RANTES and MIP- $1 \beta$ in neonatal cells. These findings suggest that neonatal neutrophils are more sensitive to phthalatemediated inhibition of PPAR- $\gamma$, which may be related to decreased anti-inflammatory signaling. (Pediatr Res 68: 134-139, 2010)
\end{abstract}

$\mathrm{D}$ i-(2-ethylhexyl) phthalate (DEHP) is the only plasticizer approved by the US Food and Drug Administration for medical use. Consequently, most polyvinyl chloride (PVC)rich medical devices contain DEHP. The release of DEHP from PVC occurs at a rate that depends on temperature, storage time, flow rates of solution through tubing, the percentage of DEHP present, and the lipophilic nature of the solution in contact with the PVC plastic $(1,2)$. Because hospitalized infants are administered fluids and medications through DEHP-containing tubing and catheters, their level of exposure to phthalates is significantly greater than any other population. In this regard, urinary metabolites of DEHP, which are indicators of internal exposure to phthalates, are several-fold higher in hospitalized infants than in the general

Received January 15, 2010; accepted April 21, 2010.

Correspondence: Barry Weinberger, M.D., Division of Neonatology, Department of Pediatrics, UMDNJ-Robert Wood Johnson Medical School, 1 Robert Wood Johnson Place, New Brunswick, NJ 08903; e-mail: weinbebi@umdnj.edu

Supported by National Institutes of Health grants HD042036, HD058019, GM034310, ES004738, ES005022, CA100994, CA132624, and AR055073. pediatric population (3). Neonates also have reduced renal clearance, which may result in even greater body burden of DEHP. DEHP is rapidly metabolized in blood and tissues to several biologically active metabolites, including mono-(2ethylhexyl) phthalate (MEHP) $(4,5)$.

In addition to well-documented adverse effects on development and reproduction (6-9), DEHP and its metabolites have been shown to exhibit proinflammatory activity. Thus, DEHP up-regulates CD11b expression on neutrophils (10) and stimulates the release of lysosomal enzymes and IL-1 by mononuclear cells $(11,12)$. Elevated phthalate levels during pregnancy have been reported to cause placental inflammation, increasing the risk of preterm delivery (13). These findings raise particular concerns in hospitalized premature neonates, who are developmentally susceptible to chronic inflammatory diseases such as bronchopulmonary dysplasia and necrotizing enterocolitis (14). The Food and Drug Administration has suggested a potential link between exposure to phthalates and the development of lung disease in premature infants $(15,16)$, and the American Academy of Pediatrics has expressed concern about DEHP exposure in children, calling for further study to quantify exposure, and examine its health effects (17). Toward this goal, these studies compared the effects of MEHP on inflammatory activity, apoptosis, and antioxidant expression in adult and neonatal neutrophils, and the potential role of PPAR- $\gamma$ on these responses.

\section{MATERIALS AND METHODS}

Reagents. DMEM, dextran, N-formyl-methionyl-leucyl-phenylalanine (fMLP), TgT, BSA, and Hanks balanced salt solution (HBSS) were purchased from Sigma Chemical Co. (St. Louis, MO). Ficoll-paque was from GE Healthcare (Piscataway, NJ). Annexin V-APC, 7-actinomycin D (7-AAD), and cytometric bead array flex sets were from BD Biosciences (San Jose, CA). MEHP was from TCI America (Portland, OR) and Amplex Red and horseradish peroxidase from Molecular Probes (Carlsbad, CA). ${ }^{1}$

Subjects and neutrophil isolation. All studies were approved by the Institutional Review Board of UMDNJ-RWJ Medical School and informed consent obtained. Umbilical cord blood was obtained from healthy term infants ( $\geq 37 \mathrm{wk}$ gestation) delivered by elective cesarean section before labor between January 2007 and April 2009. Subjects were excluded with clinical evidence of chorioamnionitis or other perinatal infections (maternal fever, uterine tenderness, or foul-smelling amniotic fluid). Subjects experiencing

Abbreviations: DEHP, di-(2-ethylhexyl) phthalate; fMLP, N-formyl-methionyl-leucyl-phenylalanine; MEHP, mono-(2-ethylhexyl) phthalate; NOX1, NADPH oxidase-1; PPAR- $\gamma$, peroxisome proliferator-activated receptor- $\gamma$; PVC, polyvinyl chloride; TgT, troglitazone 
labor were excluded because labor is associated with an inflammatory phenotype in neonatal neutrophils (18). Neutrophils were isolated by dextran sedimentation, followed by Ficoll gradient centrifugation and hypotonic lysis of erythrocytes (19). Peripheral venous blood neutrophils were collected from antecubital veins of healthy adult volunteers.

Chemotaxis. A 96-well microchemotaxis chamber was used to assess cellular migration (20). HBSS $(30 \mu \mathrm{L})$ containing $0.5 \%$ BSA and $2.4 \mathrm{mg} / \mathrm{mL}$ HEPES (HBSS/BSA), with or without fMLP $\left(5 \times 10^{-8} \mathrm{M}\right)$ or MEHP $(500 \mu \mathrm{M})$, were placed in each well of the lower chamber. A $5-\mu \mathrm{m}$ pore size polycarbonate filter was then placed over the wells and the upper chamber set into place. Fifty microliters of neutrophils $\left(1 \times 10^{5}\right.$ cells $)$ were added to the upper wells. After incubation for $45 \mathrm{~min}$ at $37^{\circ} \mathrm{C}$, the filter containing adhered, migrated neutrophils was removed and stained with Wright-Giemsa. Chemotaxis was quantified as the number of cells that migrated through the filter in 10 oil immersion fields. Neutrophils were treated with MEHP $(500 \mu \mathrm{M}), \operatorname{TgT}(2 \mu \mathrm{M}), \mathrm{MEHP}+\mathrm{TgT}$, or medium control for $1 \mathrm{~h}$ before the chemotaxis assay.

Apoptosis. Neutrophils were resuspended in DMEM containing 10\% fetal bovine serum $\left(1 \times 10^{6}\right.$ cells $\left./ \mathrm{mL}\right)$ and incubated with $\operatorname{MEHP}(100-500 \mu \mathrm{M})$, $\operatorname{TgT}(2 \mu \mathrm{M})$ or PBS control for $24 \mathrm{~h}$ at $37^{\circ} \mathrm{C}$. Cells were then suspended in Annexin binding buffer and incubated with Annexin V (1:20) and 7-AAD (1:10) (15 min, room temperature). Cells were analyzed by flow cytometry on a FACS Array Bioanalyzer (BD Biosciences, San Jose, CA). Viable, apoptotic, and necrotic neutrophil populations were gated electronically and data were analyzed using quadrant statistics based on relative Annexin $\mathrm{V}$ and 7-AAD fluorescence (21).

Hydrogen peroxide $\left(\mathrm{H}_{2} \mathrm{O}_{2}\right)$ production. Neutrophils were plated in $96-$ well dishes $\left(5 \times 10^{4}\right.$ cells/well $)$. A reaction mixture $(50 \mu \mathrm{L})$ containing Amplex Red $(25 \mu \mathrm{M})$ and horseradish peroxidase $(1.07 \mathrm{U} / \mathrm{mL})$ was added to each well, followed by MEHP $(500 \mu \mathrm{M})$ or PBS control, with or without $\mathrm{TgT}$ $(2 \mu \mathrm{M})$. Fluorescent product was measured spectrophotometrically at $1 \mathrm{~min}$ intervals for $30 \mathrm{~min}$ at $540 \mathrm{~nm}$ excitation and $590 \mathrm{~nm}$ emission on a Perkin Elmer HTS 7000 Bio Assay Reader (22).

RNA expression. Neutrophils were incubated with control, MEHP (500 $\mu \mathrm{M})$, and/or $\operatorname{TgT}(2 \mu \mathrm{M})$ for $4 \mathrm{~h}$. RNA was isolated using an RNeasy Mini kit (Qiagen). cDNA was synthesized using a High Capacity cDNA reverse transcription kit (Applied Biosystems, Foster City, CA). Real time PCR was performed using SYBR Green PCR Master Mix (Applied Biosystems) and amplified on an ABI Prism 7900 sequence detection system, using GAPDH as standard. Full-length coding sequences were obtained from GenBank. Primers were designed using Primer Express software (Applied Biosystems). Forward and reverse primers used were GAPDH, tgggctacactgagcaccag, and gggtgtcgctgttgaagtca; superoxide dismutase (SOD), gtcgtagtctcctgcagcgtc, and ctggttccgaggactgcaa; catalase, cggagattcaacactgccaa, and gaatgccegcacctgagtaa; and NOX1, ccttgcaccggtcattcttt, and cggtaaaaccggaggatcct.

Inflammatory proteins. Culture supernatants were incubated with premixed flex set beads coated with antibodies to IL- $1 \beta$, IL-6, Regulated on Activation Normal $\mathrm{T}$ Cell Expressed and Secreted (RANTES), VEGF, MIP- $1 \beta$, and IL- 8 for $1 \mathrm{~h}$ in 96 -well filtration plates. Premixed phycoerythrinlabeled detection reagent was then added to the wells. The plates were incubated at room temperature in the dark for $2 \mathrm{~h}$. Bead/protein complexes were then washed and analyzed for fluorescence intensity using a BD FACS Array Bioanalyzer. Data were analyzed using BD FCAP software (v 2.0) with five parameter curve fitting.

Statistical analysis. Experiments were repeated 6-15 times. Data were analyzed using Statistica 5.5 (StatSoft, Inc., Tulsa, OK). The effects of treatments were compared pairwise by $t$ test.

\section{RESULTS}

Initially, we compared the effects of MEHP on adult and neonatal neutrophil apoptosis. Consistent with previous studies (14), we found that spontaneous apoptosis was reduced in neonatal neutrophils relative to adult cells (Fig. 1). Treatment of both adult and neonatal neutrophils with MEHP inhibited apoptosis, but only at the higher doses of MEHP. The effects of MEHP $(500 \mu \mathrm{M})$ on apoptosis were significantly greater in neonatal, relative to adult cells. Phthalates have been reported to bind PPAR- $\gamma$, inhibiting the activity of this antiinflammatory signaling molecule (23). To analyze the role of PPAR- $\gamma$ in MEHP-induced suppression of apoptosis, we used the PPAR- $\gamma$ agonist, $\operatorname{TgT}$ (24). $\operatorname{TgT}$ was found to reverse the suppressive effects of MEHP on apoptosis in both adult and

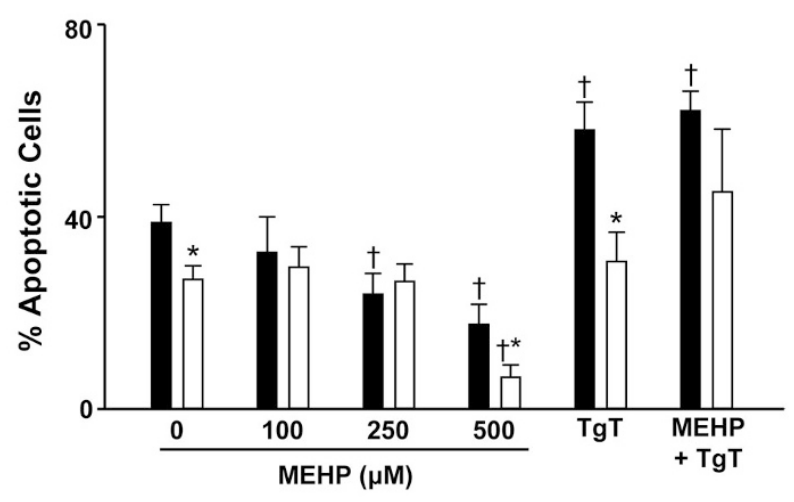

Figure 1. Effects of MEHP on neutrophil apoptosis. Adult ( $\square$ ) and neonatal ( $\square$ ) neutrophils were treated with MEHP $(0-500 \mu \mathrm{M}), \operatorname{TgT}(10 \mu \mathrm{M})$, or MEHP $(500 \mu \mathrm{M})+\mathrm{TgT}$ for $24 \mathrm{~h}$ and then analyzed for apoptosis by flow cytometry using BD FACSArray quadrant and two-dimensional histogram statistics based on relative fluorescence. Each bar represents the mean $\pm \mathrm{SE}$ $(n=3-8)$. * Significantly different $(p<0.05)$ from adult; †Significantly different $(p<0.05)$ from control.

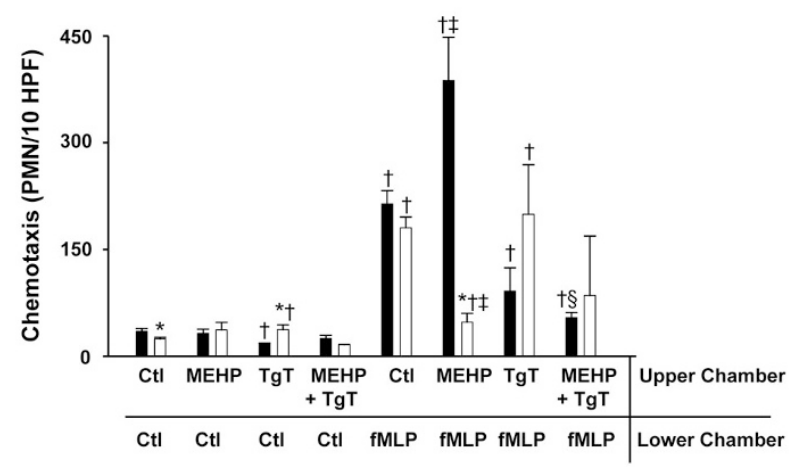

Figure 2. Effects of MEHP on neutrophil chemotaxis. Chemotaxis of adult (ם) and neonatal $(\square)$ neutrophils was assayed using microwell chambers. Cells were treated with MEHP $(500 \mu \mathrm{M})$, TgT $(2 \mu \mathrm{M}), \mathrm{MEHP}+\mathrm{TgT}$, or control $(\mathrm{Ctl})$ for $1 \mathrm{~h}$ before measurement of chemotaxis toward fMLP or medium control. Each bar represents the mean $\pm \operatorname{SE}(n=3)$. *Significantly different $(p<0.05)$ from adult; $†$ Significantly different $(p<0.05)$ from $\mathrm{Ctl} / \mathrm{Ctl} ; \ddagger$ Significantly different $(p<0.05)$ from Ctl/fMLP; §Significantly different $(p<0.05)$ from MEHP/fMLP.

neonatal neutrophils. Interestingly, $\operatorname{TgT}$ by itself stimulated apoptosis, but only in adult cells. We next compared the effects of MEHP on chemotaxis in adult and neonatal neutrophils. The bacterially-derived peptide fMLP readily induced chemotaxis in both cell types; in accord with previous studies (25), cells from adults were more responsive than cells from neonates (Fig. 2). Pretreatment of adult neutrophils with MEHP resulted in a significant increase in fMLP-induced chemotaxis. In contrast, MEHP inhibited this activity in neonatal cells. MEHP by itself had no effect on random migration in either cell type. The PPAR- $\gamma$ agonist, TgT, reduced fMLPinduced chemotaxis in both control and MEHP-treated adult neutrophils, but had no significant effects on neonatal cells.

In further studies, we compared the effects of MEHP on production of $\mathrm{H}_{2} \mathrm{O}_{2}$ by adult and neonatal neutrophils. In the absence of stimulation, the rate of $\mathrm{H}_{2} \mathrm{O}_{2}$ production was two times greater in neonatal, relative to adult neutrophils (Fig. 3). Moreover, after $30 \mathrm{~min}$, neonatal cells produced 1.7 times more $\mathrm{H}_{2} \mathrm{O}_{2}$ than adult cells. MEHP significantly increased 


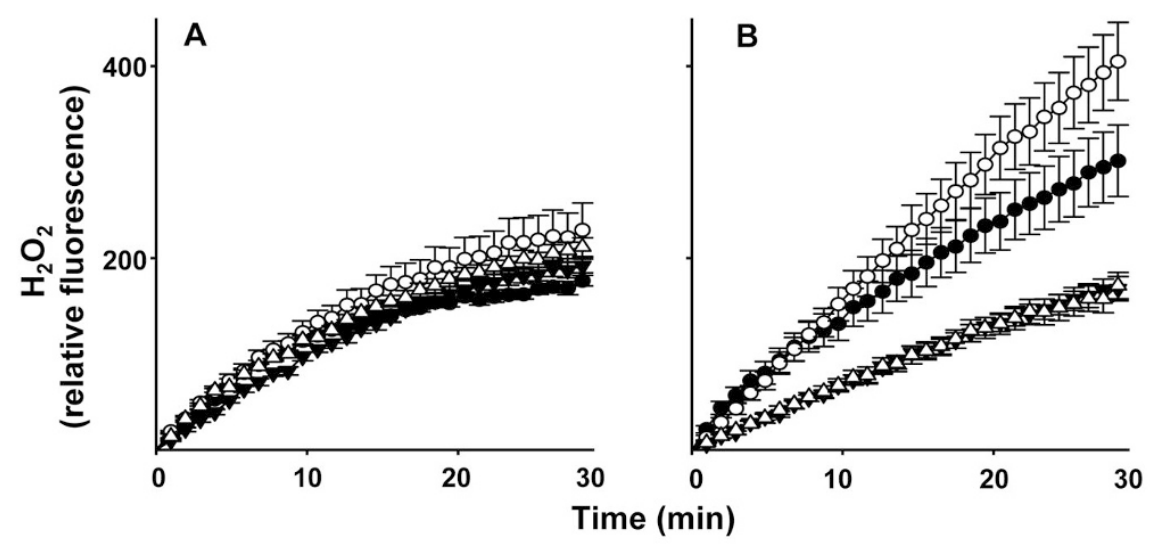

Figure 3. MEHP stimulates hydrogen peroxide production by neonatal neutrophils. Adult (panel $A)$ and neonatal (panel B) neutrophils $\left(5 \times 10^{4}\right.$ cells/well) were incubated with Amplex Red (25 $\mu \mathrm{M})$ and horseradish peroxidise, in the absence or presence of MEHP $(500 \mu \mathrm{M})$, and $\mathrm{TgT}$ or control. $\mathrm{H}_{2} \mathrm{O}_{2}$ production was quantified at 1 min intervals for $30 \mathrm{~min}$. Each point represents the mean $\pm \mathrm{SE}(n=6)$. MEHP significantly increased $\mathrm{H}_{2} \mathrm{O}_{2}$ production in neonatal cells at times $>13$ min with no effect on adult cells; $\operatorname{TgT}$ significantly attenuated this response in control and MEHP-treated neonatal cells at all time points. Control, @; MEHP, O; TgT, $\mathbf{\nabla}$; TgT + MEHP, $\triangle$.
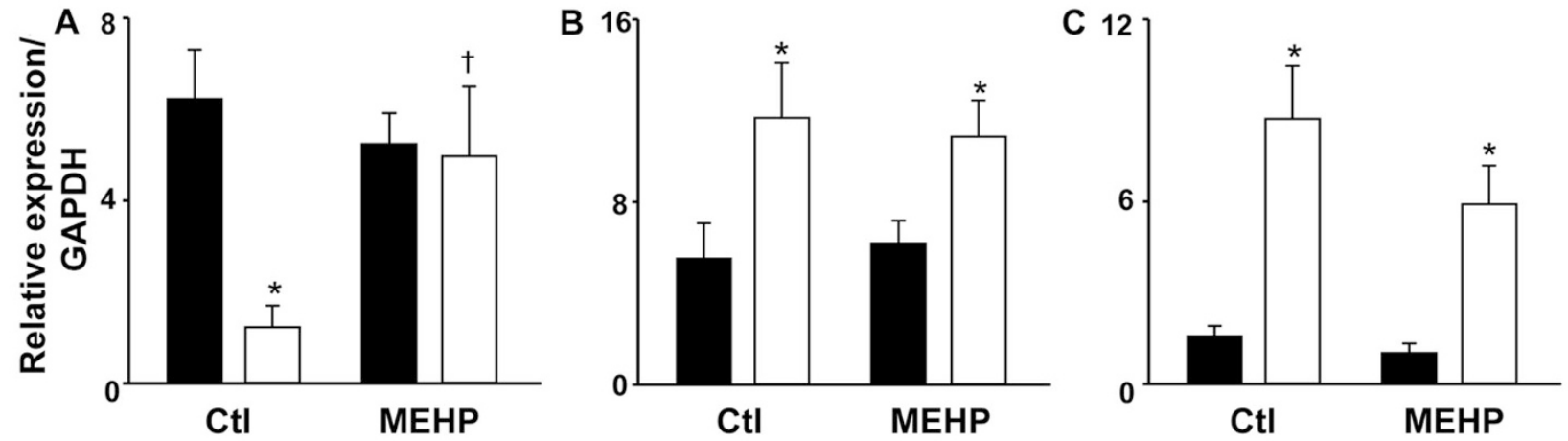

Figure 4. Effects of MEHP on expression of NOX1, SOD, and catalase in neutrophils. Adult ( $\square$ ) and neonatal ( $\square$ ) neutrophils were incubated with MEHP (500 $\mu$ M), or medium control $(\mathrm{Ctl})$ for $4 \mathrm{~h}$. mRNA expression of the $(A) \mathrm{NOX1},(B) \mathrm{SOD}$, and $(C)$ catalase genes were quantified by real-time PCR. Results were normalized to GAPDH expression. Each bar represents the mean $\pm \mathrm{SE}(n=15)$. *Significantly different $(p<0.05)$ from adult; $\dagger$ Significantly different $(p<0.05)$ from Ctl.
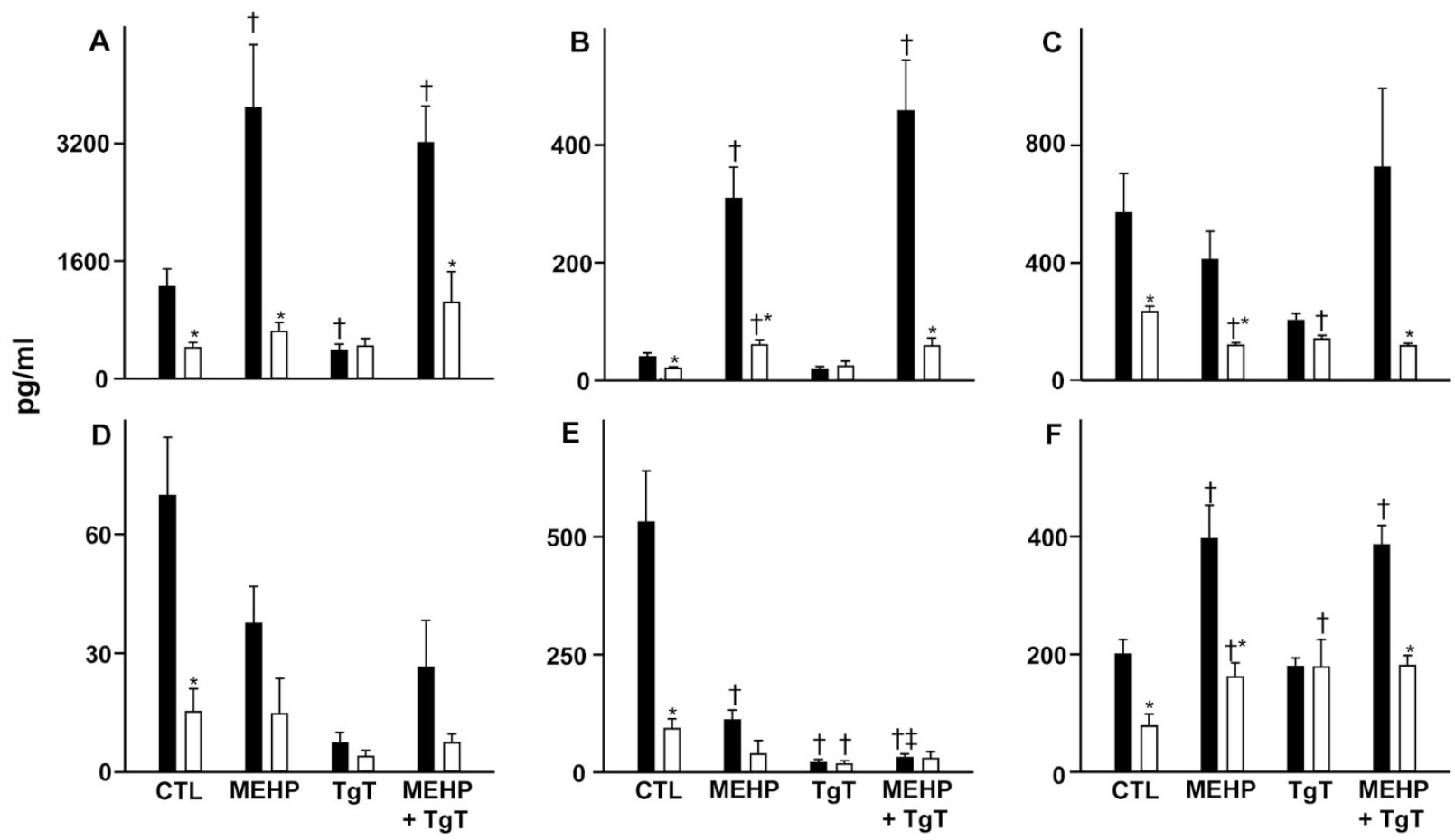

Figure 5. Effects of MEHP on inflammatory mediator production. Adult $(\square)$ and neonatal $(\square)$ neutrophils were incubated in the presence or absence of MEHP $(500 \mu \mathrm{M})$ and/or TgT $(10 \mu \mathrm{M})$ for $24 \mathrm{~h}$. The inflammatory mediators $(A)$ IL-8, $(B)$ IL-1 $\beta,(C)$ RANTES, $(D)$ IL-6, $(E)$ MIP-1 $\beta$, and $(F)$ VEGF were measured in culture supernatants using cytometric bead array analysis. Each bar represents the mean $\pm \operatorname{SE}(n=10)$. $*$ Significantly different $(p<0.05)$ from adult; $\doteqdot$ Significantly different $(p<0.05)$ from control; $\ddagger$ Significantly different from MEHP. 
both the rate (1.8 fold) and total amount (1.3 fold) of $\mathrm{H}_{2} \mathrm{O}_{2}$ produced by neonatal, but not adult neutrophils. TgT suppressed both basal and MEHP-induced $\mathrm{H}_{2} \mathrm{O}_{2}$ production by neonatal cells, with no effect on adult neutrophils. Consistent with these results, MEHP was found to up-regulate mRNA expression of NOX1, which catalyzes the production of superoxide anion, in neutrophils from neonates, but not adults (Fig. 4). However, basal levels of NOX1 were greater in adult cells.

In our next series of studies, we compared the effects of MEHP on mRNA expression of SOD and catalase, which are known to play a role in protecting against cytotoxicity and tissue damage (26). Constitutive mRNA expression of both antioxidants was greater in neonatal, when compared with adult neutrophils (Fig. 4). Treatment with MEHP had no effect on expression of these antioxidants in either cell type.

We also analyzed the effects of MEHP on neutrophil production of inflammatory proteins and chemotactic cytokines. Constitutive production of IL-1 $\beta$, VEGF, IL-6, IL-8, MIP- $1 \beta$, and RANTES was significantly reduced in neonatal, when compared with adult neutrophils (Fig. 5). MEHP stimulates IL- $1 \beta$ and VEGF production by both cell types. MEHP also stimulated IL-8 production, but only in adult neutrophils. In contrast, MEHP-inhibited MIP- $1 \beta$ production by adult neutrophils, and RANTES production by neonatal cells. No significant effects of MEHP were noted on IL-6 production in either cell type. Although TgT had no effect on MEHPinduced alterations in inflammatory protein or chemokine production in either cell type, changes were noted in constitutive production. Thus, $\operatorname{TgT}$ by itself reduced IL- 8 and MIP- $1 \beta$ production by adult cells, and RANTES and MIP- $1 \beta$ by neonatal neutrophils. In contrast, TgT stimulated VEGF production, but only in neonatal cells.

\section{DISCUSSION}

Exposure of hospitalized newborns to phthalates is a major health concern because large quantities are infused i.v. with procedures such as blood transfusions (27-29). DEHP exposure may also occur via mechanical ventilator tubes and lipid infusions, resulting in exposures more than three orders of magnitude higher in neonates relative to nonhospitalized infants and children (3,30-32). We hypothesized that MEHP exerts proinflammatory activity in neutrophils, and that this may increase susceptibility to chronic diseases. To test this, we compared the effects of MEHP on inflammatory activity of adult and neonatal neutrophils. Because serum phthalate levels in hospitalized neonates have not been reported, MEHP concentrations used in this study were calculated based on measurements in adults after prolonged exposure. Platelet apheresis can provide up to approximately $2 \mathrm{mg}$ of DEHP (33). Extrapolating to a continuous i.v. infusion in a $1-\mathrm{kg}$ infant with a blood volume of $100 \mathrm{~mL}$, and assuming rapid metabolism to MEHP, this would yield a serum concentration of approximately $1 \mathrm{mM}$. Although the rate of metabolism of MEHP in neonates is not known, it has a half-life of $6.3 \mathrm{~h}$ in mature animals (34). Therefore, doses of 100 to $500 \mu \mathrm{M}$ are expected to be within the magnitude of levels to which neutrophils may be exposed in the blood of neonates receiving intensive care.

Increased susceptibility of newborns to bronchopulmonary dysplasia and other inflammatory diseases is thought to be due to impaired resolution of inflammation and clearance of neutrophils by apoptosis $(35,36)$. Consistent with this, we have previously reported that apoptosis is reduced in neonatal neutrophils relative to adult cells; moreover, this is related to decreased responsiveness to Fas ligand and anti-inflammatory eicosanoids (14). Findings in these studies that MEHP suppresses apoptosis, and that this effect is greater in neonatal, compared with adult neutrophils, suggest that exposure of neonates to phthalates may further impair the clearance of neutrophils, exacerbating inflammatory conditions in these patients.

Neutrophils accumulate in tissues in response to chemokines generated at sites of infection or injury. IL-8 is a potent neutrophil chemoattractant; it also up-regulates expression of cell adhesion molecules (37). The present studies demonstrate that MEHP augmented fMLP-induced chemotaxis in adult, but not neonatal cells. This correlated with increased production of IL- 8 by adult neutrophils. MEHP has also been shown to induce calcium flux and up-regulate expression of the integrin, CD11b, which are important in cell motility $(10,38)$. It has previously been reported that calcium mobilization and expression of CD11b are developmentally impaired in neonatal neutrophils $(25,39)$. These defects, together with the inability of MEHP to stimulate IL-8 production in neonatal cells, may contribute to the inhibitory effects of MEHP on chemotactic responses in these cells.

Inflammatory cytokines and bacterial-derived products trigger the generation of reactive oxygen species (40). The present studies show that both adult and neonatal neutrophils constitutively generate significant quantities of $\mathrm{H}_{2} \mathrm{O}_{2}$. However, the rate of production and total amount of $\mathrm{H}_{2} \mathrm{O}_{2}$ generated were greater in neonatal cells, which is consistent with our previous observations (18). MEHP was found to stimulate $\mathrm{H}_{2} \mathrm{O}_{2}$ production by neonatal, but not adult neutrophils. These findings are in accord with reports that phthalates induce oxidative metabolism in neonatal neutrophils (41). We also found that MEHP up-regulated NOX1 expression, but only in neonatal cells. NOX1 is the major enzymatic mediator of superoxide anion generation in neutrophils (42). Increased expression of NOX1 by neonatal neutrophils is consistent with previous reports that in response to inflammatory stimuli, these cells produce greater amounts of superoxide anion relative to adult cells (43). Of note is our observation that constitutive expression of NOX1 was lower in neonatal relative to adult cells. These findings are in accord with reports that constitutive production of superoxide anion is low or undetectable in these cells (44). Interestingly, constitutive expression of SOD and catalase was elevated in neonatal neutrophils, when compared with adult cells, which supports the idea that these antioxidants are key to protecting neonates from reactive oxygen species generated in fetal and maternal circulation (45). In contrast to its stimulatory effects on NOX1 and oxidative metabolism in neonatal neutrophils, MEHP had no effect on expression of SOD or catalase. MEHP-induced increases in NOX1 and production of reactive oxygen species occur in the 
absence of increases in antioxidant production. Consistent with the idea that oxidative activity is increased in neonates, the proportion of phthalates excreted as mono (2-ethyl-5carboxypentyl) phthalate, an oxidative metabolite of DEHP, is markedly increased in neonates when compared with adults (31). Increased reactive oxygen species may also contribute to increased susceptibility of neonates to oxidant-induced tissue injury, characterized by sustained inflammation leading to cytotoxicity, apoptosis, and fibrosis.

Additional comparative studies revealed that constitutive production of IL- $1 \beta$, IL-6, IL-8, MIP-1 $\beta$, RANTES, and VEGF was significantly reduced in neonatal neutrophils when compared with adult cells. These findings are in accord with previous reports that the generation of cyokines and chemokines is developmentally impaired in neonatal cells (46). Whereas in adult neutrophils, MEHP suppressed the production of MIP-1 $\beta$, in neonatal cells, it suppressed RANTES production. MIP- $1 \beta$ and RANTES are CC chemokines that act primarily on monocytes and macrophages (47). Downregulation of these mediators by MEHP suggests that the proinflammatory effects of MEHP are mainly directed toward neutrophils. This is supported by our findings that MEHP stimulated IL-8 production in adult cells. The fact that this was not evident in neonatal cells is in accord with our findings that MEHP blocks chemotaxis in these cells. MEHP was also found to up-regulate IL- $1 \beta$ and VEGF production in both cell types. IL- $1 \beta$ is a marker of neutrophil activation during chronic inflammatory disease (48), and VEGF has been shown to mediate neutrophil adhesion and migration (49). Increased production of these mediators may represent an important mechanism contributing to MEHP-induced neutrophilic inflammation in both adults and neonates.

PPAR- $\gamma$ is a nuclear transcription factor important in downregulating the production of pro-inflammatory cytokines and reactive nitrogen species during the resolution phase of inflammation (50). PPAR- $\gamma$ agonists have been shown to reduce neutrophil-mediated lung and liver injury during endotoxemia (51). Previous studies have shown that phthalates bind to PPAR- $\gamma$, suppressing its activity (23). The PPAR- $\gamma$ agonist TgT attenuated MEHP-mediated suppression of apoptosis and stimulation of oxidative metabolism by neonatal neutrophils. These data suggest that MEHP modulates these activities in neonates by inhibiting anti-inflammatory signaling via PPAR- $\gamma$. In contrast, TgT had no effect on MEHP-induced alterations in production of inflammatory proteins or chemokines by adult or neonatal neutrophils, indicating that these effects are mediated by PPAR- $\gamma$ independent pathways. Interestingly, TgT suppressed the effects of MEHP on chemotaxis in adult neutrophils, suggesting that that the role of PPAR- $\gamma$ signaling in chemotaxis is developmentally regulated. Developmental alterations in PPAR- $\gamma$ signaling are also supported by our observation that adult and neonatal neutrophils display differential sensitivity to the effects of TgT alone. For example, TgT stimulated apoptosis and inhibited IL-8 production in adult, but not neonatal cells. It may be that PPAR- $\gamma$ plays a role in regulating neutrophil longevity and migration in adult neutrophils, and that these pathways are impaired in neonatal cells. It has been reported that prostaglandin $\mathrm{J} 2$ and other eicosanoids may be endogenous ligands for PPAR- $\gamma$, but the role of these mediators in neonatal disease is not known $(52,53)$.

Clinical case reports indicate that phthalates may contribute to neonatal inflammatory disease. For example, high levels of DEHP have been reported in the gastrointestinal tissue of infants who succumbed to necrotizing enterocolitis (54), and phthalate exposure has been implicated in chronic lung disease in premature infants (55). The present studies demonstrate that MEHP induces oxidative metabolism and up-regulates expression of NOX1 in neonatal neutrophils. This is associated with reduced apoptosis and chemotaxis. Taken together, these data suggest that neonatal neutrophils are more sensitive to phthalatemediated inhibition of PPAR- $\gamma$ signaling, which may be related to decreased basal anti-inflammatory signaling via this pathway. Understanding the inflammatory effects of phthalates in neonates may support efforts to limit or discontinue the use of phthalatecontaining medical devices in neonates.

\section{REFERENCES}

1. Kambia K, Dine T, Gressier B, Bah S, Germe AF, Luyckx M, Brunet C, Michaud L, Gottrand F 2003 Evaluation of childhood exposure to di(2-ethylhexyl) phthalate from perfusion kits during long-term parenteral nutrition. Int J Pharm 262:83-91

2. Loff S, Subotic U, Reinicke F, Wischmann H, Brade J 2004 Extraction of diethylhexyl-phthalate from perfusion lines of various material, length and brand by lipid emulsions. J Pediatr Gastroenterol Nutr 39:341-345

3. Calafat AM, Needham LL, Silva MJ, Lambert G 2004 Exposure to di-(2-ethylhexyl) phthalate among premature neonates in a neonatal intensive care unit. Pediatrics 113:e429-e434

4. Stroheker T, Cabaton N, Nourdin G, Regnier JF, Lhuguenot JC, Chagnon MC 2005 Evaluation of anti-androgenic activity of di-(2-ethylhexyl)phthalate. Toxicology 208:115-121

5. Kavlock R, Barr D, Boekelheide K, Breslin W, Breysse P, Chapin R, Gaido K, Hodgson E, Marcus M, Shea K, Williams P 2006 NTP-CERHR expert panel update on the reproductive and developmental toxicity of di(2-ethylhexyl) phthalate. Reprod Toxicol 22:291-399

6. Parks LG, Ostby JS, Lambright CR, Abbott BD, Klinefelter GR, Barlow NJ, Gray LE Jr 2000 The plasticizer diethylhexyl phthalate induces malformations by decreasing fetal testosterone synthesis during sexual differentiation in the male rat. Toxicol Sci 58:339-349

7. Moore RW, Rudy TA, Lin TM, Ko K, Peterson RE 2001 Abnormalities of sexual development in male rats with in utero and lactational exposure to the antiandrogenic plasticizer Di(2-ethylhexyl) phthalate. Environ Health Perspect 109:229-237

8. Gray LE Jr, Ostby J, Furr J, Price M, Veeramachaneni DN, Parks L 2000 Perinatal exposure to the phthalates DEHP, BBP, and DINP, but not DEP, DMP, or DOTP, alters sexual differentiation of the male rat. Toxicol Sci 58:350-365

9. Agarwal DK, Eustis S, Lamb JC, Reel JR, Kluwe WM 1986 Effects of di(2-ethylhexyl) phthalate on the gonadal pathophysiology, sperm morphology, and reproductive performance of male rats. Environ Health Perspect 65:343-350

10. Gourlay T, Samartzis I, Stefanou D, Taylor K 2003 Inflammatory response of rat and human neutrophils exposed to di-(2-ethyl-hexyl)-phthalate-plasticized polyvinyl chloride. Artif Organs 27:256-260

11. Calo L, Fracasso A, Cantaro S, Cozzi E, De Silvestro G, Plebani M, Bazzato G, Borsatti 1993 A Plasticizers induced mononuclear cells interleukin 1 production: implications with peritoneal sclerosis. Clin Nephrol 40:57

12. Bally MB, Opheim DJ, Shertzer HG 1980 Di-(2-ethylhexyl) phthalate enhances the release of lysosomal enzymes from alveolar macrophages during phagocytosis. Toxicology 18:49-60

13. Latini G, De Felice C, Presta G, Del Vecchio A, Paris I, Ruggieri F, Mazzeo P 2003 In utero exposure to di-(2-ethylhexyl)phthalate and duration of human pregnancy. Environ Health Perspect 111:1783-1785

14. Hanna N, Vasquez P, Pham P, Heck DE, Laskin JD, Laskin DL, Weinberger B 2005 Mechanisms underlying reduced apoptosis in neonatal neutrophils. Pediatr Res 57:56-62

15. Calafat AM, McKee RH 2006 Integrating biomonitoring exposure data into the risk assessment process: phthalates [diethyl phthalate and di(2-ethylhexyl) phthalate] as a case study. Environ Health Perspect 114:1783-1789

16. United States Food and Drug Administration Safety Assessment of Di(2-ethylhexyl) Phthalate (DEHP) Released from PVC Medical Devices. Available at: http:/ www.fda.gov/downloads/MedicalDevices/DeviceRegulationandGuidance/Guidance Documents/UCM080457.pdf. Accessed March 16, 2010

17. Shea KM 2003 Pediatric exposure and potential toxicity of phthalate plasticizers. Pediatrics 111:1467-1474

18. Weinberger B, Vetrano AM, Syed K, Murthy S, Hanna N, Laskin JD, Laskin DL 2007 Influence of labor on neonatal neutrophil apoptosis, and inflammatory activity. Pediatr Res 61:572-577 
19. Ferrante A, Thong YH 1980 Optimal conditions for simultaneous purification of mononuclear and polymorphonuclear leucocytes from human blood by the HypaqueFicoll method. J Immunol Methods 36:109-117

20. Boyden S 1962 The chemotactic effect of mixtures of antibody and antigen on polymorphonuclear leucocytes. J Exp Med 115:453-466

21. Sgonc R, Gruber J 1998 Apoptosis detection: an overview. Exp Gerontol 33:525533

22. Mohanty JG, Jaffe JS, Schulman ES, Raible DG 1997 A highly sensitive fluorescent micro-assay of $\mathrm{H} 2 \mathrm{O} 2$ release from activated human leukocytes using a dihydroxyphenoxazine derivative. J Immunol Methods 202:133-141

23. Hurst CH, Waxman DJ 2003 Activation of PPARalpha and PPARgamma by environmental phthalate monoesters. Toxicol Sci 74:297-308

24. Naito Y, Yoshikawa T 2004 Thiazolidinediones: a new class of drugs for the therapy of ischemia-reperfusion injury. Drugs Today (Barc) 40:423-430

25. Weinberger B, Laskin DL, Mariano TM, Sunil VR, DeCoste CJ, Heck DE, Gardner CR, Laskin JD 2001 Mechanisms underlying reduced responsiveness of neonatal neutrophils to distinct chemoattractants. J Leukoc Biol 70:969-976

26. Asikainen TM, White CW 2004 Pulmonary antioxidant defenses in the preterm newborn with respiratory distress and bronchopulmonary dysplasia in evolution: implications for antioxidant therapy. Antioxid Redox Signal 6:155-167

27. Kamrin MA 2009 Phthalate risks, phthalate regulation, and public health: a review J Toxicol Environ Health B Crit Rev 12:157-174

28. Weisbach V, Koch HM, Angerer J, Eckstein R 2006 Di(2-ethylhexyl)phthalate exposure of apheresis donors is procedure-related. Transfusion 46:1457-1458, author reply 1459

29. Inoue K, Kawaguchi M, Yamanaka R, Higuchi T, Ito R, Saito K, Nakazawa H 2005 Evaluation and analysis of exposure levels of di(2-ethylhexyl) phthalate from blood bags. Clin Chim Acta 358:159-166

30. Latini G, Avery GB 1999 Materials degradation in endotracheal tubes: a potential contributor to bronchopulmonary dysplasia. Acta Paediatr 88:1174-1175

31. Silva MJ, Reidy JA, Preau JL, Samandar E, Needham LL, Calafat AM 2006 Measurement of eight urinary metabolites of di(2-ethylhexyl) phthalate as biomarkers for human exposure assessment. Biomarkers 11:1-13

32. Plonait SL, Nau H, Maier RF, Wittfoht W, Obladen M 1993 Exposure of newborn infants to di-(2-ethylhexyl)-phthalate and 2-ethylhexanoic acid following exchange transfusion with polyvinylchloride catheters. Transfusion 33:598-605

33. Koch HM, Angerer J, Drexler H, Eckstein R, Weisbach V 2005 Di(2 ethylhexyl)phthalate (DEHP) exposure of voluntary plasma and platelet donors. Int J Hyg Environ Health 208:489-498

34. Ljungvall K, Tienpont B, David F, Magnusson U, Torneke K 2004 Kinetics of orally administered di(2-ethylhexyl) phthalate and its metabolite, mono(2-ethylhexyl) phthalate, in male pigs. Arch Toxicol 78:384-389

35. Speer CP 2006 Pulmonary inflammation and bronchopulmonary dysplasia. J Perinatol 26:S57-S62; discussion S63-64

36. Stefanutti G, Lister P, Smith VV, Peters MJ, Klein NJ, Pierro A, Eaton S 2005 P-selectin expression, neutrophil infiltration, and histologic injury in neonates with necrotizing enterocolitis. J Pediatr Surg 40:942-947; discussion 947-948
37. Scapini P, Lapinet-Vera JA, Gasperini S, Calzetti F, Bazzoni F, Cassatella MA 2000 The neutrophil as a cellular source of chemokines. Immunol Rev 177:195-203

38. Niggli V 2003 Signaling to migration in neutrophils: importance of localized pathways. Int J Biochem Cell Biol 35:1619-1638

39. Abughali N, Berger M, Tosi MF 1994 Deficient total cell content of CR3 (CD11b) in neonatal neutrophils. Blood 83:1086-1092

40. Ryter SW, Kim HP, Hoetzel A, Park JW, Nakahira K, Wang X, Choi AM 2007 Mechanisms of cell death in oxidative stress. Antioxid Redox Signal 9:49-89

41. Latini G 2000 Potential hazards of exposure to di-(2-ethylhexyl)-phthalate in babies A review. Biol Neonate 78:269-276

42. Lambeth JD, Kawahara T, Diebold B 2007 Regulation of Nox and Duox enzymatic activity and expression. Free Radic Biol Med 43:319-331

43. Tsukimori K, Komatsu H, Yoshimura T, Hikino S, Hara T, Wake N, Nakano H 2007 Increased inflammatory markers are associated with early periventricular leukomalacia. Dev Med Child Neurol 49:587-590

44. Newburger PE 1982 Superoxide generation by human fetal granulocytes. Pediatr Res 16:373-376

45. Rosenfeld W, Concepcion L 1986 Endogenous antioxidant defenses in neonates. J Free Radic Biol Med 2:295-298

46. Carr R 2000 Neutrophil production and function in newborn infants. Br J Haemato 110:18-28

47. Baggiolini M, Loetscher P, Moser B 1995 Interleukin-8 and the chemokine family. Int J Immunopharmacol 17:103-108

48. Kotecha S 1996 Cytokines in chronic lung disease of prematurity. Eur J Pediatr 155:S14-S17

49. Scaldaferri F, Vetrano S, Sans M, Arena V, Straface G, Stigliano E, Repici A, Sturm A, Malesci A, Panes J, Yla-Herttuala S, Fiocchi C, Danese S 2009 VEGF-A links angiogenesis and inflammation in inflammatory bowel disease pathogenesis. Gastroenterology 136:585-595

50. Chinetti G, Griglio S, Antonucci M, Torra IP, Delerive P, Majd Z, Fruchart JC, Chapman J, Najib J, Staels B 1998 Activation of proliferator-activated receptors alpha and gamma induces apoptosis of human monocyte-derived macrophages. J Biol Chem 273:25573-25580

51. Collin M, Patel NS, Dugo L, Thiemermann C 2004 Role of peroxisome proliferatoractivated receptor-gamma in the protection afforded by 15 -deoxydelta12,14 prostaglandin $\mathrm{J} 2$ against the multiple organ failure caused by endotoxin. Crit Care Med $32: 826-831$

52. Kuhn H, O'Donnell VB 2006 Inflammation and immune regulation by $12 / 15$ lipoxygenases. Prog Lipid Res 45:334-356

53. Scher JU, Pillinger MH 2005 15d-PGJ2: the anti-inflammatory prostaglandin? Clin Immunol 114:100-109

54. Hillman LS, Goodwin SL, Sherman WR 1975 Identification and measurement of plasticizer in neonatal tissues after umbilical catheters and blood products. N Engl J Med 292:381-386

55. Roth B, Herkenrath P, Lehmann HJ, Ohles HD, Homig HJ, Benz-Bohm G, Kreuder J, Younossi-Hartenstein A 1988 Di-(2-ethylhexyl)-phthalate as plasticizer in PVC respiratory tubing systems: indications of hazardous effects on pulmonary function in mechanically ventilated, preterm infants. Eur J Pediatr 147:41-46 